\section{Major depression caused by Wilson's disease}

\author{
Rev Bras Psiquiatr. 2014;36:184
}

doi:10.1590/1516-4446-2013-1188

Wilson's disease (WD) is an illness caused by the body's inability to release copper from the liver. ${ }^{1-5}$ It is caused by an autosomal recessive genetic alteration, located in chromosome $13,{ }^{1}$ and has an incidence of approximately 1 in every $30,000-40,000$ births. ${ }^{5}$ It generally manifests between the ages of 11 and 25 years, with hepatic symptoms, although other organs may be affected. ${ }^{1}$ In $10 \%$ of cases, psychiatric disorders manifest concomitantly with the first symptoms and signs, ${ }^{3,5}$ although they usually tend to appear later, and may present as anxiety, mood disorders, or full-blown psychosis. ${ }^{5}$ The diagnosis can be made by a thorough history and positive liver biopsy. Low serum levels of ceruloplasmin and copper, with an increase of the free ion fraction in the bloodstream; elevated copper levels in a 24-hour urine sample; and the presence of Kayser-Fleisher rings in the cornea should prompt strong suspicion of WD. ${ }^{4}$

We report the case of a 31-year-old male patient who was previously diagnosed with his first major depressive episode during the last 6 months and was medicated with several antidepressants, at adequate dosages and for adequate lengths of time, with no satisfactory response. He developed psychotic symptoms and was prescribed paliperidone $6 \mathrm{mg} /$ day as an add-on to escitalopram 20 $\mathrm{mg} /$ day. After the appearance of extrapyramidal symptoms (parkinsonism), biperiden was added to his regimen. At the time of first psychiatric examination at our service, he was still depressed. Voluntary and spontaneous attention were preserved, but he had difficulty speaking due to intense sialorrhea. On physical examination, blood pressure was $120 / 80 \mathrm{mmHg}$, the body mass index (BMI) was $21 \mathrm{~kg} / \mathrm{m}^{2}$, and the patient exhibited cogwheel rigidity and tremor at rest. Mirtazapine $30 \mathrm{mg} /$ day was prescribed and paliperidone and escitalopram were discontinued. At 2-week follow-up, he was slightly improved, but had lost a further $3 \mathrm{~kg}$. Magnetic resonance imaging of the brain showed a signal abnormality in the putamen and central part of the pons and diffuse enlargement of the subarachnoid space, inconsistent with the patient's age. A laboratory workup revealed normal renal and hepatic markers, ceruloplasmin $3.9 \mathrm{mg} /$ $\mathrm{dL}$ (reference range, 22-58 mg/dL), 24-hour urine copper $5.4 \mu \mathrm{g}$ (reference range, 3.0-5.0 $\mu \mathrm{g}$ ), and serum copper $148.12 \mu \mathrm{g} / \mathrm{dL}$ (reference range, $60-140 \mu \mathrm{g} / \mathrm{dL}$ ). Computed tomography of the abdomen showed signs of chronic liver disease with multiple hypodense nodules. A new neurological examination revealed facial diplegia, right hemilingual atrophy, muscle strength $4+/ 5+$ in the upper and lower extremities, altered deep tendon reflexes (upper extremities 2+, patellar 1+, Achilles reflex absent), akinesia, loss of postural reflexes, and paretic gait.

Due to suspicion of WD, the patient was admitted for Dpenicillamine therapy, which was titrated to a dose of $2 \mathrm{~g} /$ day after 10 weeks of hospitalization. He was discharged in stable clinical condition, although serious neurological sequelae remained. The antidepressant (mirtazapine 30 $\mathrm{mg} /$ day) was continued.

WD is a rare disease and can manifest with several central nervous system changes. ${ }^{3,5}$ Thus, one should suspect this condition when there are signs in the medical history or physical examination to suggest it, as well as in cases of treatment-resistant bipolar disorder or recurrent major depression with neurologic symptoms. The prognosis of WD can be good with timely diagnosis; hence, it is imperative that it be considered early in the differential. ${ }^{1,5}$

\section{Lucas Araújo-de-Freitas, Marlos Rocha, Vania Gondim, Lucas Quarantini, Angela Miranda-Scippa Department of Neurosciences and Mental Health, Universidade Federal da Bahia (UFBA), Salvador, BA, Brazil \\ Submitted Jun 13 2013, accepted Aug 172013.}

\section{Disclosure}

The authors report no conflicts of interest.

\section{References}

1 Bem RS, Muzzillo DA, Deguti MM, Barbosa ER, Werneck LC, Teive HA. Wilson's disease in southern Brazil: a 40-year follow-up study. Clinics (Sao Paulo). 2011;66:411-6.

2 Barbosa ER, Machado AA, Cançado EL, Deguti MM, Scaff M. Wilson's disease: a case report and a historical review. Arq Neuropsiquiatr. 2009;67:539-43.

3 Pandey RS, Swamy HS, Sreenivas KN, John CJ. Depression in Wilson's disease. Indian J Psychiat. 1981;23:82-5.

4 Brito JCF, Coutinho MAP, Almeida HJF, da Nóbrega PV. Doença de Wilson: diagnóstico clínico e sinais das "faces do panda" à ressonância magnética. Relato de caso. Arq Neuropsiquiatr. 2005;63:176-9

5 Carta M, Mura G, Sorbello O, Farina G, Demelia L. Quality of life and psychiatric symptoms in Wilson's Disease: the relevance of bipolar disorders. Clin Pract Epidemiol Ment Health. 2012;8:102-9.

\section{Is insight really necessary for diagnosis of Charles Bonnet syndrome? A case report}

Rev Bras Psiquiatr. 2014;36:184-185

doi:10.1590/1516-4446-2013-1214

Charles Bonnet syndrome is a relatively common condition in elderly patients with low visual acuity and may affect up to $12 \%$ of the patients with visual impairments. ${ }^{1}$ The syndrome is characterized by complex visual hallucinations and full or partial preservation of insight, with no other sensory hallucinations or delusions and exclusion of other mental disorders. ${ }^{1}$ Although these are the most accepted features for diagnosis of the 
syndrome, controversies remain as to its diagnostic criteria. $^{2}$ The clinical case presented herein illustrates this diagnostic discussion.

A 70-year-old housewife with 3 years of formal education, was referred to the outpatient psychogeriatric clinic because of changes in her behavior and complex visual hallucinations in which she saw, through her window, men and women killing one another and people in the bathroom. The patient began hallucinating 8 years ago after macular degeneration with consequent severe visual impairment. She was aware that the hallucinations were not real. According to her family members, she started expressing increasing irritation about 2 years prior to presentation, but continued to carry out household chores with no significant impairment. She presented no other significant mood-related or psychiatric symptoms during the interview. However, she seemed to have experienced a major depressive episode 8 years before, between the period of macular degeneration and onset of the hallucinations. It was not until 2 years before, when she began displaying intense fear and reporting that her neighbors were "killing people" and "performing rituals" that included sex and drugs, that she was referred to a psychiatrist. Despite having no specific mood-related symptoms, she began receiving antidepressants and antipsychotics in low doses, but no improvement was observed. During this period, she lost insight into her visual hallucinations, which could appear throughout the day, and began experiencing frequent delusions. Two months before presentation, she was referred to the psychogeriatric clinic. Tests were performed for dementia syndrome screening. A computed tomography scan of the head was normal for age. Other laboratory results, including thyroid-stimulating hormone (TSH), vitamin B12, VDRL test for syphilis, and HIV test, were also normal. No significant abnormalities were observed during clinical neurological examination.

A tentative diagnostic of Charles Bonnet syndrome was made, although the most accepted criteria for the diagnosis of this syndrome require insight into the hallucinations and absence of delusions. In this syndrome, hallucinations can last from a few seconds to a whole day, and can persist for years, varying in frequency and complexity, usually with preservation of insight. ${ }^{3}$ However, in this case, the diagnosis of Charles Bonnet syndrome was hypothesized because of a temporal relationship between the onset of hallucinations and macular degeneration, with no functional impairment secondary to cognitive deficits, which is required for the diagnosis of dementia. It is worth recalling that a large proportion of these patients may develop dementia. ${ }^{4}$ Furthermore, other neurological diseases were ruled out. Another important disease in the differential diagnosis is schizophrenia, but the advanced age of onset ruled out this option. Psychopharmacological treatment of the Charles Bonnet syndrome with antipsychotics has low efficacy. ${ }^{5}$ Our patient was started on a trial of olanzapine up to $20 \mathrm{mg} /$ day and showed partial remission of the psychotic symptoms.

Thus, we can conclude that the diagnosis of Charles Bonnet syndrome is complex, and, in some cases, could be considered even in the absence of critical judgment of reality, especially when the duration of disease is prolonged.

Lucas G. Romano, Maria C. Ristum, Marcos H. Chagas Department of Neuroscience and Behavior, Ribeirão Preto Medical School, University of São Paulo, Ribeirão Preto, SP, Brazil

Submitted Jul 15 2013, accepted Aug 182013.

\section{Disclosure}

The authors report no conflicts of interest.

\section{References}

1 Teunisse RJ, Cruysberg JR, Hoefnagels WH, Verbeek AL, Zitman FG. Visual hallucinations in psychologically normal people: Charles Bonnet's syndrome. Lancet. 1996;347:794-7.

2 Lerario A, Ciammola A, Poletti B, Girotti F, Silani V. Charles Bonnet syndrome: two case reports and review of the literature. J Neurol. 2013;260:1180-6.

3 Cammaroto S, D'Aleo G, Smorto C, Bramanti P. Charles Bonnet syndrome. Funct Neurol. 2008;23:123-7.

4 Lapid MI, Burton MC, Chang MT, Rummans TA, Cha SS, Leavitt JA, et al. Clinical phenomenology and mortality in Charles Bonnet syndrome. J Geriatr Psychiatry Neurol. 2013;26:3-9.

5 Hughes DF. Charles Bonnet syndrome: a literature review into diagnostic criteria, treatment and implications for nursing practice. J Psychiatr Ment Health Nurs. 2013;20:169-75. 